\title{
LA FICCIÓN COMO COARTADA DEL APÁTRIDA: UN MILAGRO INFORMAL DE FERNANDO IWASAKI
}

\author{
José Manuel Camacho \\ Delgado \\ Universidad de Sevilla
}

\begin{abstract}
The article analyzes the book of short stories entitled "Un milagro informal" (2003) (An Informal Miracle), written by the Hispano-Peruvian author Fernando Iwasaki, in the context of the new trends in Peruvian narrative literature. In a sense, the book's table of contents allows us to realize that Iwasaki has selected the most representative tales from his genre of short-story telling. Besides, he has anthologized himself and has introduced new tales that provide evidence of a clear evolution in his literary work. Thus, he eliminates any kind of boundaries, not only in those aspects involving subject matters and styles, but also in the different genres. This evolution is clearly represented in the author's forms, the stylistic, even linguistic distance that are present in the tales written in Seville in recent years, when compared with those written in Lima during the eighties. Nonetheless, despite the numerous metamorphoses that Iwasaski's writings present, there are four main subjects that cover transversally all his short-story telling output, namely, 1) the imaginary element, that bursts abruptly into the world of realism, 2) the eroticism, trimmed with jocular and ludic elements, 3) the parody, presented mainly in the detective genre and 4) the intertextual puns. These four elements are perfectly connected and invite most of the time the use of a sort caustic and corrosivehumour.
\end{abstract}

La literatura adelgaza las fronteras del tiempo y el espacio, convierte al lector en un curioso impertinente que sucumbe a la nostalgia de lo no vivido, e invita a todo autor a transformar lo clásico en contemporáneo y sacudir la actualidad encima de la tradición. También permite trazar la sinuosa identidad de aquellos escritores cuya azarosa vida no está tipificada en los recetarios administrativos, escapa de los registros civiles convencionales y se resiste a entrar en las etiquetas de una sociedad que trata de tabular y codificar para comprender. En ese terreno escurridizo de la creación a donde no llega el canon más convencional se encuentra el escritor hispanoperuano Fernando Iwasaki.

El libro de Fernando Iwasaki, Un milagro informal (2003) ${ }^{1}$, se compone de catorce relatos y un texto preliminar, a modo de prólogo, que encierra toda una poética del cuento. Con el título "Por qué escribo relatos o para cuándo novela" el narrador peruano demuestra el conocimiento profundo que tiene no sólo de la elaboración del cuento, sino también de sus presupuestos teóricos. En la mejor tradición de los manifiestos programáticos que abundaron a comienzos del siglo $\mathrm{XX}^{2}$, parodiados por Horacio Quiroga en su "Decálogo del perfecto cuentista" (1925), Iwasaki habla del cuento pero introduciendo la nota autobiográfica y personal, convirtiendo el texto en un microrrelato donde se habla de Perú y

\footnotetext{
${ }^{1}$ Madrid, Alfaguara, 2003. Cito siempre por esta edición.

${ }^{2}$ Para una visión de conjunto de las teorías sobre el cuento resulta de gran interés el libro de Fernando Burgos (editor), Los escritores y la creación en Hispanoamérica, Madrid, Editorial Castalia, 2004.
} 
de Sevilla. En el prólogo se hace referencia a la concepción del género que tenía Cortázar, expuestas en "Algunos aspectos del cuento" (1963) 3 cuando por medio de una metáfora boxística "señala que en las novelas hay que ganar por puntos y en los relatos por knock$o u t$ " (p. 11). Iwasaki, inspirado en un rasgo esencial de nuestro actual modus vivendi, como es la "creación rápida y la comida ligera", se sirve de un símil culinario para establecer la diferencia entre un cuento y una novela:

"La novela puede ser poco hecha y el cuento debe estar bien cocido. La novela siempre engorda y el relato suele tener las calorías justas. La novela una vez abierta aguanta muy bien en la nevera y el cuento tiene que consumirse de inmediato. La novela lleva conservantes y el relato es pura fibra. La novela siempre consiente una recalentada, mientras que el cuento -como la película- « sólo se fríe una vez». La novela es un potaje caliente de hervores casi intestinales y el relato una comida fría de bricolaje vegetal. La novela quita el hambre y el cuento abre el apetito" (pp. 11-12).

Algunos de los cuentos ya habían sido publicados con anterioridad en sus libros Tres noches de corbata 4 (1987) y A Troya, Helena (1993), remontándose los primeros textos a 1987. En cierto sentido, el índice del libro nos permite ver que Iwasaki ha seleccionado lo más representativo de su cuentística, se ha antologado a sí mismo y ha introducido nuevos relatos que apuntan a una clara evolución de su quehacer literario, eliminando todo tipo de fronteras, no sólo en los temas y los estilos, sino también en los géneros. Una evolución que se percibe en sus formas, en la distancia estilística, incluso lingüística, que tienen los cuentos escritos en los últimos años en Sevilla, con respecto a los creados en Lima en los años ochenta. No obstante, a pesar de las múltiples metamorfosis que presenta su escritura, hay cuatro temas fundamentales que recorren de forma trasversal su producción cuentística: 1) el elemento fantástico, que irrumpe de forma violenta en el mundo de la realidad, 2) el erotismo, ribeteado de elementos lúdicos y jocosos, 3) la parodia, fundamentalmente en el género policial y 4) los juegos intertextuales. Cuatro elementos que aparecen perfectamente trenzados y que invitan la mayor parte de las veces a la utilización de un humor cáustico y corrosivo.

\section{LA IRRUPCIÓN DE LO FANTÁSTICO}

Es precisamente el elemento fantástico el que más puede llamar la atención en sus libros, puesto que la tendencia entre muchos de los nuevos narradores es justamente la de huir de este tipo de incursiones. Iwasaki parte siempre de una situación real e inmediata. El escenario que propone es normal, cotidiano, rutinario incluso. Crea así para el lector un hábitat familiar, lleno de elementos costumbristas, sobre el que opera la irrupción sorprendente de lo fantástico, siguiendo una tendencia visible en la cuentística peruana de los últimos años ${ }^{6}$. Voy a destacar en este sentido dos cuentos: "El ritual" y "Erde".

\footnotetext{
${ }^{3}$ Recogido en Fernando Burgos, op. cit., pp. 238-250. También encontramos en este volumen el texto clásico de Cortázar: "Del cuento breve y sus alrededores", pp. 250-257.

4 "El ritual”, "La sombra del guerrero", "La otra batalla de Ayacucho", "Taki Ongoy" y "La invención del héroe".

5 A.de Chatellus, "La escritura sin fronteras de Fernando Iwasaki Cauti" en Actas del coloquio internacional Fronteras de la literatura y de la crítica, Poitiers, CRLA-Archivos, 2004.

6 J. Martínez Gómez, "Informe sobre el cuento peruano de finales del siglo (1970-2000) enEl Cuento en Red, Otoño de $2001, n^{\circ} 4$.
} 
En "El ritual" narra la historia de una profanación y del robo del cadáver de un niño, llamado Dieguito, muerto de cáncer. Todo lo ocurrido en torno a Dieguito lo conocemos gracias a la mirada y el lenguaje infantil de un hermanito más pequeño, llamado Sebastián, quien desde su inocencia recrea el dolor de Dieguito y cómo su enfermedad mortal es un elemento desestructurador de la familia. El cuento es un pequeño drama en miniatura que por momentos recuerda a "Macario" de Juan Rulfo. El niño- narrador informa de los intentos médicos por salvarle la vida, de las duras sesiones de quimioterapia, de los continuos viajes a hospitales de EEUU y todo ello salpicado de pequeñas referencias a la cotidianidad traumática de la familia que nos sitúan en una clase alta de la sociedad limeña. Frente a esta visión de la enfermedad, que podríamos encuadrar dentro del "pensamiento científico", el elemento mágico y la conciencia mítica son introducidas en el relato por medio de la criada de la casa, la negra Pancha, quien hace de intermediaria para poner en contacto al niño con el mundo esotérico de la hechicera Madame Pacheco. Las visitas son siempre clandestinas, a escondidas de los padres. En las sesiones de espiritismo, Madame Pacheco utiliza todo su repertorio de métodos y fórmulas, recurriendo a un laboratorio variopinto que recuerda al de La Celestina. Frente a las plantas medicinales que utiliza para extirpar el mal, que nos situaría en una concepción naturista de la medicina, la curandera se sirve del humo del tabaco, frota el cuerpo del niño con un gato negro, lo baña con una sopa, le reza a un pájaro disecado y le practica una sangría ritual. A pesar de todo, Dieguito muere, y la Pancha y Madame Pacheco son detenidas. No obstante, la tragedia familiar conoce otro siniestro bucle: la tumba de Dieguito aparece un mes más tarde profanada ("han prosanado su tumba") y el cuerpo del niño desaparecido. Esta "normalidad luctuosa" se rompe de forma violenta por una información que nos da el narrador infantil, justo al finalizar su historia: "Yo también quiero mucho a Dieguito, pero me da miedo y quiero estar abajo con todos. Si la Pancha estuviera aquí le pediría que le subiera Suspiro Limeño o Arroz con Leche, pero la Pancha está en la cárcel y él debe tener hambre. Cuando entró por la ventana me asusté, todo negro y apestoso, pero si no fuera por la medallita no lo habría escondido en mi ropero" (p. 27). Si inquietante resulta este dato, alterado desde la mitología infantil, no menos inquietante resulta su comentario: "Me da miedo estar aquí arriba. La casa huele a muerto, a podrido" " (p. 23). Como ocurre en la literatura mítica y heroica la medalla confiere identidad al personaje, es una marca de presentación. Quien se esconde en el cuarto de Sebastián es el "cadáver del hermano muerto" que sigue añorando el mundo de los vivos, en una secuencia de claro aliento rulfiano, que recuerda, no obstante, el motivo de "La flor de Coleridge", tal y como lo recrea Borges ${ }^{8}$.

El segundo relato, "ERDE", ahonda en esta veta fantástica, sin la intermediación de la mirada infantil. Erde Amöbe es una adolescente que estudia en una academia para preparar su ingreso en la Universidad Católica de Lima. Descrita por el narrador como una Lolita limeña, criatura sensual, "un poco fuera de este mundo, de una inocente hermosura infantil que las pusiera más allá del bien y del mal” (p.165), trae a la memoria, de forma inevitable a otros personajes femeninos, como Remedios la Bella de García Márquez o Susana San Juan de Rulfo. Pero no es sólo la belleza hiperbólica de Erde lo que zarandea al protagonista del cuento, sino la inteligencia rápida y vibrante que exhibe en todo momento,

\footnotetext{
${ }^{7}$ La cursiva es mía.

${ }^{8}$ Borges, citando a Coleridge, dice así: "Si un hombre atravesara el Paraíso en un sueño, y le dieran una flor como prueba de que había estado allí, y si al despertar encontrara esa flor en su mano... ¿entonces, qué?” enOtras Inquisiciones, Obras Completas II, Buenos Aires, Emecé Editores, 1989, p. 17.
} 
así como sus extraordinarios conocimiento en Historia y Mitología. De hecho, el texto viene encabezado por una cita de Hesíodo, perteneciente a Teogonía, en la que se cuenta cómo el temible y violento Tifón, después de haber retozado con la Tierra, engendró a feroces hijos $^{9}$. La vida de Erde está llena de enigmas de difícil solución. No sabemos hasta el final del relato por qué sus calificaciones escolares bajan de forma estrepitosa cada final de mes, o las relaciones inexistentes que mantiene con sus padres o el aislamiento constante en el que vive. Un hecho insólito en el cuento nos traslada del ambiente académico y los problemas de una adolescente un tanto extravagante a un relato donde el drama psicológico y los elementos de terror marcan el ritmo de la narración:

\begin{abstract}
"Nadie supo cómo entraron ni a qué hora, pero alrededor de las once unos alaridos espantosos despertaron a la servidumbre. Los charcos de sangre indicaban una carnicería terrible e incluso el forense llegó a desvanecerse cuando observó los trozos humanos diabólicamente fagocitados por el suelo. Cerbero, el perro guardián de la casa, había descuajeringado a un par de fulanos que encontró en el cuarto de Erde. ¿Robo?, ¿secuestro?, ¿violación?”(p. 172).
\end{abstract}

Este episodio origina toda una ristra de leyendas en torno a la reputación de Erder. Los rumores la sitúan en antros de malvivir, en las salas de strip-tease, en lupanares de poca monta, provocando todo tipo de altercados y cataclismos, transformada en una "especie de Miss Hyde", "una suerte de virgen viciosa de los bajos fondos de Lima" (p. 173) que recuerda por momentos a la Lolita de Nabokov. La tensión del relato crece cuando el protagonista nos informa de los extraños asesinatos que mensualmente se producen en las cercanías de la casa de Erder:

\begin{abstract}
"Muchas madrugadas me sentí sobrecogido a la hora de regresar, pues los asaltos y atentados estaban a la orden del día. Obviamente yo no era un candidato al secuestro, mas sí una potencial víctima del siniestro «maricón descuartizador» que tenía en jaque a la ciudad: sus presas eran siempre hombres a los cuales seducía con su aspecto feminoide, para luego filetearlos y castrarlos con salvaje ferocidad. A pesar de la recomendación policial de no levantar a nadie pasadas las once, cada mes se cometía un crimen que espeluznaba a los limeños. Una cosa estaba clara: el homicida no podía ser mujer porque su fuerza era brutal y sus aullidos carrasposos. Por eso la prensa sensacionalista le había bautizado como «Jackie la destripadora». Al menos Erde estaba fuera de peligro" (pp. 174-175).
\end{abstract}

El protagonista-narrador, su profesor, consigue después de muchas galanterías y no pocas palabritas tiernas hacerle el amor a Erder Amöbe. Descubre entonces que tras el coito la dulce criatura se metamorfosea en una terrible medusa llena de "menstruos" que exigen un sacrificio ritual al final de cada mes. No es Jackie la destripadora, quien perpetra los horrendos asesinatos, sino Erde Medusa (Amöbe). Con este final sorprendente, Iwasaki da una puntada más en ese complejo arquetipo de la literatura como es la mujer fatal. Pandora, Semíramis, Judith, Cleopatra o Salomé están presentes en la construcción de este personaje. Y muy especialmente la Lolita de Mempo Giardinelli, llamada Aracelli Tannembaum, icono del eterno perverso femenino.

\title{
2. APUNTES DEL NATURAL. LOS CHISPAZOS ERÓTICOS
}

El erotismo es otro elemento común en todos los cuentos de Un milagro informal. En su cuento "Hawai Cinco y Medio", título inspirado obviamente en la popular serie televisiva

9 (“Con ella cuentan que el terrible, violento y malvado Tifón tuvo contacto amoroso, con la joven de vivos ojos. Y preñada, dio a luz feroces hijos..."). 
"Hawai Cinco Cero", tres mujeres adultas, cuya vida sentimental es una suma de decepciones, deciden establecer una relación sexual con jóvenes adolescentes a los que pagan por los servicios prestados. Cada una de ellas busca diversión y placer en los adolescentes, pero sobre todo un poco de cariño. Ellos por su parte necesitan el dinero para cumplir una ensoñación: viajar a las playas de Hawai para practicar el surf. El encuentro entre las tres parejas tiene lugar en un célebre motel limeño, llamado "Cinco y Medio", un lugar furtivo y clandestino donde las tres parejas podrán dar rienda suelta a todo tipo de juegos amorosos. El cuento se recrea en las escenas eróticas, en las que el escritor demuestra una gran sensibilidad.

El erotismo en su faceta más dolorosa lo encontramos en "A Troya, Helena". Una cita del canto III de la Ilíada sitúa una vez más el relato en una dimensión clásica, que viene dada en esta ocasión por el propio título. En el cuento, un profesor universitario, prematuramente envejecido a pesar de sus escasos treinta años, contempla estupefacto, al entrar en su casa, los restos de una batalla amorosa que ha dejado el camino regado de prendas íntimas. Al entreabrir la puerta contempla la belleza insólita de Helena, a través del espejo del ropero, "sentada sobre la barriga de un amante enardecido que la hacía subir y bajar, entrar y salir" (p. 127). Iwasaki construye un Kamasutra en miniatura ofreciéndole al lector un amplio repertorio de posturas inverosímiles y no pocos motivos para espolear la imaginación sexual. La recatada esposa del orden doméstico aparece ante el sufrido marido como una "Melusina insaciable", una devoradora de hombres. El protagonista, ante la posibilidad de asesinar a los amantes, decide darle una oportunidad a la comprensión y convertir la escena punzante en una nueva cicatriz para el recuerdo. "Con el tiempo- dice el narrador- olvidé la escena pecaminosa que reverberó en el armario, mas a veces resuena en mis oídos ese ruido tan triste que hacen dos cuerpos cuando se aman" (p. 130).

También la revisión de la Historia está presente en esta colección de cuentos. No en vano, Fernando Iwasaki posee una formación como historiador y a esta ciencia social ha dedicado trabajos como, El comercio ambulatorio en Lima (1989), El descubrimiento de España (1996) o Extremo Oriente y Perú en el siglo XVI (1992). Tres son los textos claves que encontramos en el libro: "La sombra del guerrero", "La otra batalla de Ayacucho" y "Taki Ongoy". El primero de ellos, titulado "La sombra del guerrero" tiene un claro componente autobiográfico. El protagonista del cuento recibe la visita, un tanto sorprendente e inesperada, de un antiguo samurai que había mantenido relaciones con su abuelo. Yoshitaro Kohatsu cuenta la historia de su vida, convertido en prófugo y traidor al emperador japonés. Durante cincuenta años su adversario, Takachi Kawashita, sigue los pasos del traidor hasta encontrarlo, pero en el momento de la ejecución comprende que ya nada tiene sentido porque el mundo ha cambiado demasiado y ni siquiera el Japón mantiene sus señas de identidad. Verdugo y víctima se convierten así en grandes amigos y el cumplimiento de la promesa queda postergado para la siguiente generación. El protagonista del cuento recibe entonces el regalo de una katana milenaria con la que debe devolver el honor a su familia y restablecer el bushido, el código del samurai.

También son dos generaciones distintas las que se enfrentan en "La otra batalla de Ayacucho": un abuelo y su nieto, que puede ser leído como un homenaje al abuelo materno con el que el escritor tuvo muy poca relación. Articulado en su morfología sobre la historia oral de "que viene el lobo", un abuelo que se siente próximo a la muerte decide dejar lo más importante de su herencia al nieto al que apenas ve por la incomprensión de su yerno. Este regalo es una colección de soldaditos de plomo que representan a las fuerzas enfrentadas en 
la batalla de Ayacucho. El abuelo le habla de "Sucre al frente del ejército libertador, la caballería de La Mar y a Gamarra como Jefe de Estado Mayor" (p. 89) y le habla de la grandeza de Simón Bolívar. ¿Qué son estos héroes del pasado frente a la fascinación que ejerce en el niño la figura de Sky walker y los héroes y villanos de la guerra de las galaxias? No son las armas de fuego y los cañones de pólvora los que llaman la atención de Eduardito, sino la espada láser y los cañones protónicos. El "invencible ejército de Ayacucho" aparece así derrotado por unas cuantas luces de bengala y el anciano vuelve a su soledad con la certeza de que ahora sí llegará a su vida el temible lobo que ponga punto y final a su propia batalla.

También destacamos el cuento “Taki Ongoy” ('Danza del viento') en el que nos cuenta cómo "el Pachacámac y la guaca Titicaca había reunido a todas las demás guacas en el Cuzco, que es el centro del mundo, para organizarlas en la guerra contra el barbudo dios de los españoles" (p. 121). De la misma forma que Chocne había sido tocado por un rayo y había recibido por medio de la luz las claves para llevar a cabo su rebelión contra los españoles, cuatro siglos más tarde, el mecánico Ramiro Becerra cree ser la reencarnación de Chocne después de haber recibido una descarga eléctrica en el taller donde trabaja. El cuento presenta una estructura claramente circular, donde se superponen y entrecruzan los planos temporales y en donde el sentido de la venganza contra el poder da unidad a las dos épocas históricas.

\section{ENTRE LA LUPA Y LA CARCAJADA. LA PARODIA Y EL HUMOR EN EL GÉNERO POLICIAL}

Iwasaki conoce a la perfección el género policial, al que siempre vuelve como lector, tal y como demuestra en dos de sus relatos: "Un muerto en Cocharcas" y "La invención del héroe", pero lo hace desde la parodia y la desmitificación, lo que le permite inocular el virus del escepticismo y la incredulidad en su mirada sobre la realidad peruana. "Un muerto en Cocharcas" pertenece a una de las tipologías más reconocidas del género negro, como es el crimen perfecto en una habitación cerrada. Como recuerda Mempo Giardinelli, en sus estudios sobre la novela negra, tenemos "por un lado la novela enigma, novela-problema o de cuarto cerrado: son los textos clásicos, en los que casi invariablemente la trama consiste en descubrir a un criminal que se esfuma en el espacio: la típica situación de asesinato en una habitación cuyas puertas y ventanas están cerradas por dentro, el cadáver en el piso y ninguna pista visible. Claro está: alguien ha cometido el crimen y ése es el misterio, ${ }^{, 10}$. El modelo alcanza su máxima expresión con la literatura de Agatha Cristie, especialmente con su novela El misterio del cuarto. "En estos espacios cerrados, escribe Hubert Pöppel, se solían encontrar los ocho, diez o doce miembros del elenco, pertenecientes a la misma clase social: uno o dos morían, uno o dos -el detective y eventualmente su ayudante y narradorinvestigaban, los demás eran sospechosos y casi siempre tenían algo por esconder, por ende, nunca decían toda la verdad. A pesar de ello, el detective lograba disociar mentiras, semiverdades y verdades para encontrar, en el tiempo predeterminado -el fin de semana, el viaje, el plazo de sus vacaciones-, el o los culpables que siempre pertenecían al círculo interno del elenco" $"$.

\footnotetext{
${ }^{10}$ M. Giardinelli, El género negro, México, Universidad Autónoma Metropolitana, 1996, Colección Molinos de Viento, p.15.

${ }^{11}$ H. Pöppel, La novela policíaca en Colombia, Medellín, Editorial Universidad de Antioquia, 2001, p. 15.
} 
En "Un muerto en Cocharcas" el escenario del crimen es la propia casa de la víctima. Frente a la literatura propia del tema, que suele recrear espacios sofisticados, elegantes y suntuosos, con decorado exquisito, muebles de época y sirvientes con librea, en el relato de Iwasaki, la descripción de la casa aparece en clave irónica, con sus manteles de plástico pegajoso, las botellas vacías de cerveza hacinadas encima de la mesa, "la radiola barata y chillona" soltando los compases de una "huaracha estridente", a pesar de la presencia del cadáver, lo que permite dar "un toque surrealista al escenario del crimen" (p. 29). El cuerpo que encuentran los investigadores del caso, el sargento Temoche y su ayudante, el cabo Fiestas, ha sido salvajemente maltratado, vejado aún después de su muerte, lo que indica un verdadero ensañamiento por parte del asesino o de los culpables, que, por supuesto, se encuentran en el interior de la pieza. Si el lugar del crimen ha sido parodiado, otro tanto ocurre con las causas y agentes que han podido intervenir en él. De hecho, los detectives descubren, en el simulacro de interrogatorio, que el muerto era un sujeto indeseable, violento y borracho; por tanto, todos y cada uno de los miembros de la familia -y de su entorno- parecen estar sobrados de razones para perpetrar el espeluznante crimen. Tal y como informa el cabo Fiestas:

"Tenemos a todos los que estaban desde el principio. El que lo boleteó al dueño del santo tiene que ser uno de estos angelitos. Acá la señora es la viuda, la chica es la hija, este zambito es el novio, el otro es un cuñado, el señor dice que era compadre del muerto y éste era su palanca porque el finado era microbusero. Si me permite, mi sargento, yo creo que el palanca es el más sospechoso" (p. 30).

Los propios sospechosos van dándole pistas de cómo hubieran realizado el crimen. La esposa despechada, contenta con habérselo quitado de enmedio, le aclara al sargento: "Yo no lo maté, porque si yo lo hubiera matado habría usado mis cosas de cocina" (p. 37). El tono paródico del cuento prosigue con la falta de clarividencia del propio detective, romo en iniciativas, carente de intuición y de método, y cada vez más confundido con el caso: "No lograba descifrar el misterio del asesinato y a la vez todo le parecía muy simple. Cada uno tenía sus propios motivos para matar al muerto y sin embargo todos declararon su inocencia con odio, con rencor y con cinismo" (p. 38). Ante este panorama, no descarta incluso que la muerte sea por circunstancias naturales ${ }^{12}$.

Frente al detective clásico de la literatura negra, caracterizado siempre como un tipo duro con su entorno e implacable en su relación con las mujeres, el sargento Temoche aparece descrito como una criatura desvalida y desamparada frente a la inmensa autoridad de su mujer, llamada Hortensia. Es ella la que manda en la casa y la que impone las normas, a voz en grito, incluida la hora de llegada del sargento. El desenlace del relato nos permite ver cierta estructura circular: el sargento Temoche, metido en la cama y amenazado por su mujer, se siente igual que el muerto de Cocharcas:

"Entonces pensó en Hortensia y se acordó que ella también sabía dónde guardaba las balas, la pistola y la metralleta. De pronto escuchó un batir de ollas, el vértigo filoso de la licuadora y un espeluznante escarceo de metales. En su memoria reverberó una frase: «Si yo lo hubiera

\footnotetext{
12 "Ya en la morgue nos dirán de qué murió, pero a lo mejor el conchasumadre hasta se murió de infarto después de la bronca y entonces ahí todos soltaron la mierda que tenían adentro. ¿Te das cuenta, Fiestas? Se descobraron con el cadáver como si fuera una piñata" (p. 39).
} 
matado habría usado mis cosas de la cocina». Así que sacó la matraca coreana y se puso a dormir con el dedo en el gatillo. «Por si las huevas», pensó” (p. 40).

El segundo de los relatos policiales es una verdadera pieza maestra, dentro de la parodia del género negro. En "La invención del héroe" se narra la historia del mayor Yauri, quien se ve catapultado a la primera fila de la policía de investigaciones contra el terrorismo y la violencia, cuando es retirado su suegro, el general Causo. Lo que en un principio podría ser motivo de regocijo y alegría se convierte en desazón y amargura porque a Yauri lo que le gusta es el servicio tranquilo y administrativo y no estar en la PIP (Policía de Investigaciones del Perú), con todos los riesgos y tensiones que eso conlleva. Iwasaki convierte a este "antihéroe" en el detective principal del cuento y le busca un ayudante inesperado, llamado Rodolfo, que no es más que un profesor de literatura de la Universidad, especialista en novela negra y policial, que ha cautivado a su esposa con su perspicacia e ingenio. Desde el principio hay una incompatibilidad manifiesta entre el profesor Rodolfo y el mayor Yauri. Éste no soporta de Rodolfo su aparente mediocridad, su risita inoportuna y recurrente, su atuendo vulgar y su predilección por el arrocito con leche. Por su parte, Rodolfo siente una admiración burlesca por todo lo detectivesco, ya proceda de la literatura, el cine y la televisión o la vida real.

La relación entre ambos personajes se produce siempre en torno a una cena en la que no puede faltar el arrocito con leche. Rodolfo, después de saciar su apetito goloso, hace gala de una enorme inteligencia y de un conocimiento extraordinario en asuntos policiales. Gracias a su bagaje literario pone en jaque permanente al mayor Yauri, convertido por momentos en una versión peruana del miles gloriosus. La relación "profesional" entre ambos comienza con el caso de las hermanas Gandolfo, muchachas ricas y distinguidas de la sociedad limeña, que han sido raptadas a plena luz del día. Rodolfo desmonta una por una las medidas que ha ordenado Yauri, siguiendo siempre algún argumento policial de su acervo literario. Al final, el caso se resuelve por la vía literaria, más que policial, y Yauri tiene que reconocer que en ese doblete, es el ayudante quien piensa y resuelve el caso. Lo que en un principio es una humillación para el mayor, pronto se convierte en un éxito inesperado, con gran relevancia social y felicitaciones institucionales, tal y como lo recoge la prensa peruana. Yauri aprovechará esta circunstancia para resolver -vía Rodolfo- todo caso que se presente en su entorno. Los aciertos de Rodolfo se deben a sus lecturas. Como reconoce el personaje:

"No hay crimen que no se corresponda con un modelo de la literatura policial. Por ejemplo, este caso me hizo recordar El secuestro de Miss Blandish ... No, pues. Aquí en Lima no fue. Es una novela de James Hadley Chase inspirada en Santuario de Faulkner pues; je, je. Gracioso, ¿no? Entonces, de lo que se trata es de comenzar a leer historias policiales y de aplicarlas en su trabajo. Además, usted podría imitar a detectives famosos como Gideon Fill, Maigret o Lestrade. ¿Le gustaría?... Claro, pues, ¿no?; je, je... Pero debe comenzar por el principio leyendo algo facilito. Sería bueno que leyera algo de Poe... Poe, pues... ¿No sabe quién fue Edgar Allan Poe?... No, pues. De dónde, pues, ¿no?; je, je... Poe fue el creador de la literatura policial y sus cuentos están bien para usted... Para usted que recién empieza, pues. Ahora déjeme comer mi arroz con leche que es mi postre favorito... ¡Mmmmuuuummmm!... Está rico, ¿no?; je, je” (pp. 147-148).

Es así como Yauri se inicia en la literatura detectivesca, leyendo "El misterio de Marie Rôget" y "Los crímenes de la calle Morgue" de Poe, y queda fascinado con "ese Dupin [que] era medio raro: ni un golpe, ni un balazo..., sólo labia y puro coco" (p. 148). Fernando 
Iwasaki hace en este relato un verdadero alarde de sus conocimientos de literatura policial, negra y de misterio, recurriendo a todo tipo de sutiles referencias para resolver los distintos casos con los que tendrá que enfrentarse esta singular pareja de detectives. Es así como Yauri consigue desarticular a un grupo subversivo, el COAD (Comando Obrero de Ataque Directo), dedicado a la extorsión y los asesinatos selectivos, por medio de Las muertes concéntricas de Jack London. La solución estriba en que todos los grupos terroristas se hacen la competencia y el caso se resuelve en un tiroteo entre los COAD y una parte de Sendero Luminoso. De esta forma, la fama y el prestigio del mayor Yauri se convierten en tema nacional:

"Ése fue el inicio rutilante del mayor Ronald Yauri. Su trabajo, estratégicamente apoyado por las cotidianas cenas de arrocito con leche, le convirtió en el agente más solicitado y famoso del Perú. Sin embargo, lo que más llamaba la atención del periodismo eran dos cosas: la erudición del mayor en literatura policial, de donde obtenía las claves para resolver todos sus casos, y -por otro lado- su prodigiosa memoria, que le permitía citar de corrido -como el Inspector Appleby de Michael Innes- párrafos enteros de sus lecturas favoritas y el inventario de los nombres de autores, obras y personajes que poblaban su vasto repertorio (...) De esta manera, la prensa difundió cómo La carta robada de Poe y La cara amarilla de Conan Doyle le ayudaron a solucionar un repugnante caso de chantaje; que Agatha Christie fue la fuente de inspiración que le permitió desentrañar el misterio del crimen del Ferrocarril Central; que Un huésped extraño de Belloc Lowndes puso tras las rejas al despiadado descuartizador del Olivar de San Isidro; que Mujer de blanco de Wilkie Collins le sirvió para rescatar a una dama de sociedad del manicomio en que había sido internada por sus parientes para cobrar la herencia y, finalmente, que la estratagema utilizada por Flambeau en $L a$ cruz azul le había conducido a la captura del asesino enviado contra el arzobispo de Lima. Con todo, su triunfo más espectacular consistió en la trampa que les tendió a los funcionarios de la Oficina de Contribuciones del Ministerio de Economía, quienes proporcionaban a los secuestradores los nombres de los candidatos al plagio (Yauri se limitó a responder que ya Holmes había hecho lo mismo para desbaratar a La liga de los pelirrojos). Por último, una atenta lectura de Emma Zunz y El impostor inverosímil Tom Castro -ambos de Borges- le llevó a sugerir la reapertura del juicio sobre el asesinato de un conocido magnate de la pesca.

- ¡Yauri!- le gritaba admirado el coronel Charún-. Usted me hace acordar a Gamboa, el detective de la televisión" (pp. 151-152).

En "La invención del héroe" se citan además las aventuras de Monsieur Lecoq de Gaboriam, a Futrelle, Si muriera antes de despertar de William Irish, con su detective ciego, llamado Max Carrados; aparece Earl Derr Biggers y su detective chino, Charlie Chan, e incluso ayuda a encontrar la espada de Pizarro siguiendo El ritual de Musgrave de Conan Doyle. De hecho, la popularidad de Yauri es de tal magnitud que es nombrado uno de los "diez hombres 10 del Perú" (p. 156), llegando a participar como miembro del jurado en un concurso de relato policial.

Sin embargo, el mundo idílico en el que se mueve el mayor se hace añicos cuando le llegan rumores de que su mujer anda en enredos amorosos con el dichoso profesor y éste le amenaza con revelar la verdad ante la prensa, poniendo en evidencia su impostura. Yauri decide entonces librarse del incómodo testigo -y de paso, de su propia esposa- y cometer el crimen perfecto, siguiendo, claro está, el ideario de sus lecturas favoritas. Recurre a textos que le pueden ayudar a cometer un asesinato impecable. Lee entonces ¿Muerte natural?, de Dorothy Sayers, El ananá de hierro de Phillpotts, El hombre que asesinó en público de Roy Vickers, el relato "La puerta y el pino" de Stevenson. El plan consiste en envenenar a los 
amantes por medio del "arrocito con leche", haciéndolo pasar por un ajuste de cuentas de algún grupo mafioso, y para ello traza su macabra venganza siguiendo la novela El caso de los bombones envenenados, de Anthony Berkeley.

Antes de ejecutar su proyecto, Yauri pide por última vez ayuda al sesudo profesor para eliminar a los capos del cártel de Lima. En la resolución del caso, Rodolfo introduce un nuevo elemento, la literatura épica, en un pasaje que trae a la memoria las opiniones vertidas en El túnel de Sábato ${ }^{13}$ :

"Le habló de los arquetipos y de la literatura épica («En el mundo moderno, los héroes policiales son los herederos de los héroes épicos -explicaba Rodolfo-. ¿No conoce la literatura épica?... No, pues, de dónde, ¿no?; je, je»), y de cómo podía convertirse en un transformador del mundo («No, pues; je, je. Del mundo policial, pues») hasta llegar a ser el prototipo de los futuros oficiales de la PIP (...) Serías grande, Yauri; más grande que todos tus personajes favoritos juntos (...) Eso de la literatura épica le había impresionado: si los héroes policiales eran conjonudos, los épicos tenían que ser la cagada" (p. 161).

La soberbia y la vanidad se convierten en una trampa moral para Yauri. Después de leer la Ilíada y la Odisea y comparar a su mujer con una nueva Penélope, llega a la conclusión de que le gusta más el mundo policial: "eso de ser héroe épico estaba bien jodido porque todos terminaban machucados o hasta las huevas. En cambio, los detectives sí eran indestructibles: Ellery Queen, Pepe Carvalho, el Sargento Cuff y Dupin habían escapado mil veces de la muerte. ¿El mismo Holmes no se había salvado del empujón que le dio el Profesor Moriarty en las cataratas? Sí, pues. Los héroes policiales eran más chéveres que los otros" (p. 162).

La solución del cuento, y de la propia vida de Yauri, parte del equívoco de una lectura errónea del texto de Connan Doyle, El sabueso de los Baskerville. Como ya hiciera el propio Sherlock Holmes, quien había acechado durante toda una noche a los criminales en una fábrica abandonada, Yauri hace lo propio para desmontar el cártel de Lima y arrogarse así el brillo de la fama. No obstante, en el último momento vive una suerte de iluminación, con resonancias borgeanas, cuando comprende que su futuro está también escrito en un cuento, "La muerte y la brújula" de Borges. Como le ocurre a Erik Lönnrot, llega a la conclusión de que él mismo será la próxima víctima, que ha sido llevado al lugar del asesinato por una mente perversa como la de Rodolfo (nuevo Red Scharlach), que ha planeado hasta en sus últimos detalles este formidable laberinto en el que va a ser engullido. En ese momento final llega a una especie de aleph en el que comprende todo: comprende que ha caído en una trampa perfectamente diseñada desde el principio por Rodolfo, comprende que va a morir solo como le ocurrió a Hércules Poirot en su última aventura y comprende entonces el sentido último del argumento de La muerte y la brújula. Al final, Yauri, confundiendo las verdades de la realidad con las de la literatura, recordó a los héroes épicos "siempre machucados, siempre hasta las huevas.. ¿Tal vez reconoció en su muerte el ciclo heroico?... ¿Acaso supo que moriría repitiendo un arquetipo?... No, pues; je, je... De dónde, pues, ¿no?” (p. 164).

\footnotetext{
${ }^{13}$ En una de las discusiones literarias que tienen lugar en El túnel, a propósito de la novela policial, donde se cita en clave humorística al propio Borges ("se lo diré a Georgi”), Hunter expone lo siguiente: “-Mi teoría- explicó- es la siguiente: la novela policial representa en el siglo veinte lo que la novela de caballería en la época de Cervantes. Más todavía: creo que podría hacerse algo equivalente a Don Quijote: un sátira de la novela policial" (Madrid, Cátedra, 1986, p. 130). En cierto sentido, Iwasaki propone su particular sátira del género en "Un muerto en Cocharcas" y en "La invención del héroe".
} 


\section{JUEGOS INTERTEXTUALES: SOBRE LA VALENTÍA Y EL CORAJE}

A lo largo de su trayectoria, el escritor Fernando Iwasaki ha demostrado su profundo conocimiento de lo mejor de nuestra tradición literaria ${ }^{14}$ y son muchas las referencias intertextuales que utiliza para su propia creación. En este sentido, su relato "El derby de los penúltimos" toca uno de los puntos de mayor interés para el escritor, como es el rescate de los escritores olvidados por su tradición, en la persona de Félix del Valle. "Mi interés en rehabilitar su figura, comenta Iwasaki, se origina en mi admiración por los escritores desleídos en las dos acepciones del término: porque no son leídos y porque se disuelven. Es una forma de ser borgeano, cuando él dice que el destino de todo escritor es el olvido"

"El derby de los penúltimos", reivindicado por el autor como el relato más importante y de mayor calado del libro, comienza con una cita de Cansinos Assens ${ }^{16}$. Iwasaki se sirve del tópico literario del manuscrito encontrado ${ }^{17}$ para dibujar un espléndido fresco literario de comienzos de siglo XX:

"En una librería de viejo de Montevideo que saldaba los retales de la biblioteca de Xavier Abril de Vivero, adquirí un baúl desportillado donde sesteaban postales antiguas, retratos dedicados, servilletas manuscritas y todos esos cachivaches inverosímiles que atesoran los náufragos y los desterrados. Allí encontré los cuadernos de Froilán Miranda -peruano peregrino, escritor apócrifo y viceversa-, quien apuró una vida borrascosa y galante. Las prosas que siguen las he espigado de aquellos diarios, como austero desagravio a su memoria" (p. 61).

El relato es una magnífica recreación del ambiente cultural de tres importantes ciudades -Lima en 1916, Madrid en 1939 y Buenos Aires en 1944- a través de una serie de temas típicamente borgeanos, como son el coraje y el valor, representados en la controvertida figura de Félix del Valle, pero vistos desde un punto de vista absolutamente original que recuerda, por momentos, el desenlace del cuento "Emma Zunz" (El Aleph, 1948). El primer momento de la narración transcurre en la Lima de 1916. El narrador dibuja el ambiente bohemio de la ciudad, la salida nocturna de los poetas locales, sus itinerarios novelescos, la vida prostibularia con sus paraísos galantes y el trajín de los fumaderos de opio. Con gran destreza, Iwasaki da vida a las rivalidades literarias existente entre los distintos grupos vanguardistas. Unos son seguidores de Verlaine y miran hacia París, como la meca del arte moderno; otros se sitúan bajo el magisterio de Valle-Inclán, y tienen en Madrid la

14 J. L. De la Fuente, "Fernando Iwasaki Cauti: las metamorfosis de la escritura", en New Peruviang Writing, Leeds, Trinity and All Saints-University of Leeds, 2000, pp. 81-100.

${ }^{15}$ F. Toloza (entrevista), "Fernando Iwasaki: La patria de un escritor son sus libros y sus lecturas" en La Capital, En la misma entrevista Iwasaki revela algunos datos importantes sobre Félix del Valle, "un escritor peruano que también existió realmente como Forcada Cabanellas. Del Valle vivió en España. Salió del Perú en los años 20 y en España vivió intensamente la República. Su único libro en España salió en una editorial donde también editaban Rafael Alberti, José Bergamín, Benjamín Jarnés. Cuando los republicanos pierden, Del Valle se exilia en la Argentina y llega con recomendación de Cansinos Assens, termina publicando en Caras y Caretas y aquí publica cuatro libros en editorial Schapire, dos sobre Sevilla, uno sobre Toledo y otro sobre Madrid".

${ }^{16}$ Son muchos los cuentos que comienzan con una cita histórica o literaria, que apunta, en cierto sentido, a la labor de investigación del escritor. En este sentido, son muy interesantes las reflexiones realizadas por Adélaïde de Chatellus en su ensayo "La escritura sin fronteras de Fernando Iwasaki Cauti, art. cit.

${ }^{17}$ Sobre la actualización del tópico del manuscrito encontrado puede consultarse el artículo de C. García Gual, "Un truco de la ficción histórica: el manuscrito reencontrado", en 1616: Anuario de la Sociedad Española de Literatura General y Comparada, Madrid, 1996, n 10, pp. 47-60. 
referencia de la modernidad. Iwasaki reconstruye los ambientes sofisticados y decadentes de la capital peruana, con sus enfrentamientos literarios y personales, representados en las figuras de Ventura García Calderón y Abraham Valdelomar. Éste último, fundador de la revista Colónida (1916), fue el artífice de una época caracterizada por la atmósfera refinada y decadente, considerada por Luis Alberto Sánchez como una "belle époque peruana". El narrador que cuenta la historia -apenas si tiene dieciséis años- envuelve esta parte del relato de una atmósfera de idealización, cuando no de mitificación, en donde Félix del Valle aparece visto como un "demonio artístico y sensual que nada tenía que ver con las refinadas quimeras parisinas de sus correligionarios (...) Ni Verlaine ni Baudelaire habrían resistido los insomnios líricos que irisaban su mirada" (p. 66). La desmitificación del personaje llega al final de esta primera parte del relato, cuando Valle muestra toda su cobardía en una disputa política que a punto está de costarle la vida.

La segunda parte del relato tiene lugar en el Madrid de 1939, poco después de finalizada la contienda civil, en una atmósfera asfixiante y belicosa, donde todavía resuenan el traqueteo de las ametralladoras y el estruendo de las bombas. En esta difícil situación, franquistas y falangistas instauran un modelo de estado que no busca la reconciliación, sino la venganza. Es la España del hambre y las enfermedades, de las sotanas en el gobierno y las cartillas de racionamiento. En medio de la desolación sobrevive a duras penas un número considerable de artistas y escritores que deambulan por una ciudad que se ha convertido en una verdadera "corte de los milagros". Iwasaki introduce en su texto a escritores claves del periodo como Ramón Gómez de la Serna, Jacinto Benavente o Jardiel Poncela; no obstante, es la figura de Cansinos Assens -y el mundo ultraísta que le rodea- la que parece concitar toda la admiración del escritor:

"Cansinos era de una altura tan grande como su tristeza, una mezcla de rabino y enterrador. Su expresión de caballo místico se desdibuja cuando los dientes de piano brotaban enormes bajo el bigote entrecano y desflecado. Era sabido que traducía más de quince idiomas y las malas lenguas decían que vivía amancebado con una hermana a quien dedicaba sonetos incestuosos y desgarrados. Aquellos poetastros mugrientos le alcanzaban al maestro gurruños de papel emborronados de poemas que yo imaginaba perpetrados con la caligrafía sucia de las uñas negras. Pero Cansinos los leía con teológica solemnidad y luego les propinaba algún elogio conmiserativo, encadenando parrafadas largas, melódicas y preñadas de metáforas que los poetas del arroyo agradecían como un sucedáneo alimenticio" (p. 70).

El narrador de la historia, Froilán Miranda, se encarga de sacar de España a los peruanos liberales, cuyas vidas corren peligro. En su contacto con Cansinos Assens éste le habla de Rubén Darío, de Vicente Huidobro, de Verlaine, de Santos Chocano y de Joaquín Edwards Bello, dejando para el lector hermosas reflexiones sobre el cante jondo y el flamenco (que tan bien conoce el propio Iwasaki por su actividad profesional) que se escucha en lo garitos miserables de la época. Esta segunda parte se cierra de forma similar a la primera. Ante la llegada amenazante de los falangistas, Valle, defensor a ultranza de la legalidad republicana, comenzó a "largar contra la República, los rusos, las chekas y los comunistas que sólo querían pisotear nuestra civilización occidental y cristiana" (p. 75). La desilusión de la primera parte se convierte en verdadera decepción por el carácter blando y pusilánime del protagonista: "Todo aquel simulacro se me antojó innecesario y vergonzoso; de una sangrante cobardía” (p. 75).

La tercera parte transcurre en Buenos Aires, en 1944. Es aquí donde vuelven a encontrarse Froilán Miranda y Félix del Valle, dos "transterrados sin país y sin familia". 
Como dice el narrador "Ambos tuvimos una patria y los dos la perdimos. Ambos quisimos un país que dejó de existir. Sólo nos pertenecían la noche y la memoria, hasta que la hora más oscura nos olvidara del todo. Valle decía que nuestras vidas eran como el «derby de los penúltimos», una carrera de perdedores donde sólo el caballo ganador esquivaba el desolladero" (p. 77). A pesar de estas circunstancias, se van a convertir en testigos excepcionales de uno de los grupos más importantes de las letras argentinas, integrado por Vicky (Victoria Ocampo), Chivi (Silvina Ocampo), Fito (Adolfo Bioy Casares) y Cocolucho $^{18}$ (Jorge Luis Borges).

También en este último tramo del relato Félix del Valle va ser puesto a prueba -en esta ocasión no por razones políticas, sino artísticas- cuando un cantaor gitano lo reta a un duelo de cuchillos. Ve en esta oportunidad que le ofrece el azar una forma de reconciliarse con su pasado "porque un hombre acosado por sus cobardías ha soñado mil veces cómo empuñar un cuchillo; porque un hombre deshonrado ha previsto minuciosamente cómo recuperar la honra perdida; porque un hombre indefenso es impredecible cuando acomete mortal" ( $p$. 80). El gitano "arrojó a los pies de Valle un puñal que brilló como un pitón de plata o como un relámpago negro" (p. 80). El episodio debe ser leído como un homenaje a "El Sur", uno de los cuentos más célebres de Borges sobre cuchilleros y compadritos ${ }^{19}$.

A diferencia de la cobardía demostrada en los episodios anteriores, Valle toma ahora la iniciativa, se arma de coraje y valor, y se enfrenta al gitano retador, dejándole en el vientre "un recado tajante y visceral" que encenderá la imaginación del joven Borges. Al narrador le hubiera gustado contarle a su interlocutor que Valle "en realidad no era un valiente, pero en sus delirios Cocolucho había convertido esa chusca trifulca en un desafío épico junto a los muros de Troya, en una batalla vikinga en las costas de Irlanda y en el duelo infinito de dos navajas embrujadas" (p. 81). Es así como Iwasaki recrea la mitología de la violencia, convirtiendo al joven Borges en un personaje, gracias al sueño de otro escritor.

Finalizamos este recorrido con dos cuentos que completan su viaje estilístico, lingüístico y personal. En "La jumelle fatale" un escritor peruano afincado en Sevilla se topa con una criatura hermosa y esotérica, nacida el 6/6/66, lo que le confiere cierta condición maligna. El cuento ahonda en la sensualidad y en el erotismo, pero también plantea el conflicto de la identidad. Como dice el narrador, "Por lo menos fuera del Perú yo tenía lascoartadas del apátrida $^{20}$, del aprendiz de escritor o simplemente del latino" (p. 13). Tanto en este relato como en el siguiente,"El vuelo de la libélula", Iwasaki retrata el mundo de la alta sociedad sevillana. En este segundo texto asistimos a la doble vida de una niña bien, llamada Macarena, criada en la Sevilla opulenta, educada en los mejores colegios, con una vida programada dentro del orden y la familia y cuyo fracaso sentimental va a propiciar su ingreso en el Opus Dei como miembro numerario. "El vuelo de la libélula" no sólo reconstruye el viaje de su propia vida, sino también los desplazamientos que realiza en

\footnotetext{
${ }^{18}$ A Borges lo describe como un "tipo sonriente y empollón, de una blancura enfermiza como la lecha vomitada", al que "le gustaban los clásicos ingleses, las novelas policiales, Las mil y una noches y la poesía gauchesca. Mientras me hablaba me cogía del brazo como si no me viera o para verme mejor, y esa ambigüedad me ponía nervioso" (p. 78).

${ }^{19}$ Son muchos los momentos en los que Borges hace referencia al cuchillo como una víbora. Quiero, no obstante, destacar la poderosa imaginería que se dibuja de este arma -por momentos, utensilio y herramienta- en su poema "Milonga de Jacinto Chiclana" (Para las seis cuerdas, 1965).

${ }^{20}$ La cursiva es mía. Este cuento, de corte autobiográfico, nos ofrece pistas valiosas para interpretar la evolución temática y formal del escritor.
} 
avión para encontrarse con un hombre rudo e inculto, un camionero vasco, con el que vive una historia apasionada y visceral. Después de las sesiones amorosas él le canta siempre "Dale a tu cuerpo alegría, Macarena".

En estas dos últimas historias, Perú puede o no aparecer como una evocación lejana, prácticamente difuminada en la ficción. Han desaparecido los topónimos peruanos, los espacios del Perú, sus personajes y situaciones y ha desaparecido el lenguaje vigoroso y exultante, empedrado de peruanismos, propio de sus primeros cuentos. En un texto leído en la Cartuja, en junio de 2003, Iwasaki hacía la siguiente reflexión:

"Muchos críticos y especialistas universitarios definen lo «latinoamericano» en función de la
identidad nacional, del conflicto social, de la némesis indígena o de los ecosistemas
amenazados, y cuando no encuentran dichos ingredientes en una novela mexicana, chilena o
argentina, le niegan fulminantes su naturaleza hispanoamericana. Así las cosas, llegados a
este punto debo admitir que la condición de latinoamericano me es inverosímil. ¿Por qué
conformarnos con ser de un solo sitio si podemos ser de todas partes y de ninguna?

La trayectoria literaria de Fernando Iwasaki representa a la perfección la propia evolución de una parte de la narrativa hispanoamericana. Afincado en Sevilla hace más de veinte años, o sea, la mitad de su vida, presume de tener un abuelo japonés, otro italiano, de tener antepasados indígenas y tres hijos nacidos en Sevilla. Dice en la intimidad que no ha perdido un país, sino que ha ganado otro. Que no sólo es peruano y limeño, sino también sevillano y español ${ }^{22}$. Que su verdadera patria es su lengua y su memoria, porque es ahí donde el hombre fragua lo esencial de su identidad, por eso, su literatura debe ser entendida como un bálsamo frente a la nostalgia y la distancia. Ésa es su coartada como escritor, la coartada del apátrida.

\section{REFERENCIAS BIBLIOGRÁFICAS}

CORNEJO POLAR, Antonio (1988): "Profecía y experiencia del caos: la narrativa peruana de las últimas décadas" en Literatura peruana hoy: crisis y creación (Karl Kohut y José Morales Saravia editores), Frankfurt/Main-Madrid, Veuvert/Iberoamericana, pp. 23-34.

COX, Mark R., "Perspectivas hacia una definición de la narrativa andina peruana contemporánea" www.andes.missouri.edu/andes/Comentario/MRC_Perspectivas.html.

DE CHATELLUS, Adélaïde (2004): "La escritura sin fronteras de Fernando Iwasaki Cauti" en Actas del coloquio internacional Fronteras de la literatura y de la crítica, Poitiers, CRLA-Archivos; en www.fernandoiwasaki.com

DE LA FUENTE, José Luis (2000): "Fernando Iwasaki Cauti: las metamorfosis de la escritura”, en New Peruviang Writing, Leeds, Trinity and All Saints-University of Leeds, pp. 81-100.

\footnotetext{
21 Palabra de América, Barcelona, Seix Barral, 2004, p. 119.

${ }^{22}$ Fernando Toloza (entrevista), "Fernando Iwasaki: La patria de un escritor son sus libros y sus lecturas" en $L a$ Capital, file:///A/noticia_154561.shtml.
} 
GARCÍA RAMOS, Arturo, "Un milagro informal: La parodia como cuento" en fille:///A/milagro.html.

GIARDINELLI, Mempo (1996): El género negro, México, Universidad Autónoma Metropolitana, Colección Molinos de Viento, 1996.

IWASAKI, Fernando, "Santa Prosa de Lima. Literatura, Centralismo y Globalización en el Perú de los 90". Conferencia pronunciada en el Instituto Cervantes de Leeds (Inglaterra) el 3/5/2003, en wysiwyg: //1/file:/A/iwasaki2.html.

IWASAKI, Fernando (2004): "No quiero que a mí me lean como a mis antepasados" en Palabra de América, Barcelona, Seix Barral, pp.104-122.

JARA JIMÉNEZ, Cronwell (1988): "Visión de la violencia y del paisaje urbano de Lima en dos nuevas novelas" en Literatura peruana hoy: crisis y creación (Karl Kohut y José Morales Saravia editores), Frankfurt/Main-Madrid, Veuvert/Iberoamericana, pp. 120-134.

KOHUT, Karl (1988): "Literatura peruana hoy: crisis y creación" en Literatura peruana hoy: crisis y creación (Karl Kohut y José Morales Saravia editores), Frankfurt/Main-Madrid, Veuvert/Iberoamericana, pp. 11-20.

MARTÍNEZ GÓMEZ, Juana (2001): "Informe sobre el cuento peruano de finales del siglo (1970-2000) en El Cuento en Red, Otoño, n ${ }^{\circ} 4$.

NIÑO DE GUZMÁN (1988): Guillermo, "Ficción y crisis: una mirada a la narrativa peruana contemporánea" en Literatura peruana hoy: crisis y creación (Karl Kohut y José Morales Saravia editores), Frankfurt/Main-Madrid, Veuvert/Iberoamericana, pp. 39-46.

RIVERA MARTÍNEZ, Edgardo (1984): "La narrativa peruana hoy", Revista de Crítica Literaria Latinoamericana, $2^{\circ}$ semestre, Año X, $\mathrm{n}^{\circ}$ 20, pp. 323-326.

TOLOZA, Fernando (entrevista), "Fernando Iwasaki: La patria de un escritor son sus libros y sus lecturas" en La Capital,

VV.AA. (2004): Palabra de América, Barcelona, Seix Barral.

VILANOVA, Núria (1996): "Dinámica de la narrativa peruana reciente", Bulletin of Hispanic Studies, LXXXIII, pp. 289-296.

VILCHES, Amalia, "Fernando Iwasaki: el libro de buen amor" en $X$ Simposio Internacional sobre Narrativa Hispánica Contemporánea. La ironía en la Narrativa Hispánica Contemporánea en http://www.fernandoiwasaki.com.

ZAVALETA, Carlos (1992): "Algunos mitos o clichés en la narrativa peruana", Cuadernos Hispanoamericanos, $\mathrm{n}^{\circ}$ 509, pp. 114-121. 